\title{
Cardiac Structure and Function in Men with Prostate Cancer Receiving Androgen-Deprivation Therapy and the Effects of Recreational Small-Sided Football Training: A Randomized Controlled Trial
}

\author{
Jakob Friis Schmidt1,2*, Lars Juel Andersen ${ }^{3}$, Jacob Uth ${ }^{4}$, Therese Hornstrup ${ }^{2,4}$, Jesper Christensen ${ }^{4}$, \\ Julie Midtgaard ${ }^{4,5}$, Klaus Brasso', Peter Krustrup",8, Mikael Rørth', Peter Riis Hansen' ${ }^{1}$ \\ ${ }^{1}$ Department of Cardiology, Copenhagen University Hospital, Gentofte, Denmark \\ ${ }^{2}$ Department of Nutrition, Exercise and Sports, Centre for Team Sport and Health, University of Copenhagen, Copenhagen, Denmark \\ ${ }^{3}$ Department of Cardiology, Roskilde Hospital, Roskilde, Denmark \\ ${ }^{4}$ The University Hospitals Centre for Health Care Research (UCSF), Copenhagen University Hospital, Rigshospitalet, Denmark \\ ${ }^{5}$ Department of Public Health, University of Copenhagen, Copenhagen, Denmark \\ ${ }^{6}$ Copenhagen Prostate Cancer Center, Department of Urology, Copenhagen University Hospital, Rigshospitalet, Denmark \\ ${ }^{7}$ Sport and Health Sciences, University of Exeter, Exeter, Great Britain \\ ${ }^{8}$ Department of Sports Science and Clinical Biomechanics, SDU Sport and Health Sciences Cluster (SHSC), University of Southern \\ Denmark, Odense, Denmark \\ ${ }^{9}$ Department of Oncology, Copenhagen University Hospital, Rigshospitalet, Denmark \\ Email: *Jakob.Schmidt@ifi.ku.dk
}

How to cite this paper: Schmidt, J.F., Andersen, L.J., Uth, J., Hornstrup, T., Christensen, J., Midtgaard, J., Brasso, K., Krustrup, P., Rørth, M. and Hansen, P.R. (2017) Cardiac Structure and Function in Men with Prostate Cancer Receiving Androgen-Deprivation Therapy and the Effects of Recreational Small-Sided Football Training: A Randomized Controlled Trial. World Journal of Cardiovascular Diseases, 7, 308-322.

https://doi.org/10.4236/wjcd.2017.79029

Received: May 31, 2017

Accepted: September 25, 2017

Published: September 28, 2017

\begin{abstract}
Purpose: Androgen deprivation therapy (ADT) is a cornerstone in prostate cancer (PCa) management that prolongs $\mathrm{PCa}$-free and overall survival, but effects of ADT on human cardiac function have not been investigated. We used echocardiography to examine cardiac structure and function in patients with prostate cancer receiving ADT and to determine whether an exercise intervention can elicit cardiac adaptations in these subjects. Methods: Forty-three patients with prostate cancer receiving ADT were randomized to 12 weeks football training (ST group; $\mathrm{n}=20$ ) or usual care (control [CO] group; $\mathrm{n}=23$ ). Cardiac function was assessed at baseline and after 12 weeks by comprehensive echocardiography. Peak oxygen consumption, blood pressure and peripheral microvascular function was also measured. Results: At baseline, no considerable echocardiographic abnormalities were observed. In the ST group, increases in left ventricular diastolic function variables including E/A ratio $(P=0.03), E^{\prime}(P=0.016), E_{\text {TDIcolor }}^{\prime}(P=0.040)$ and in left atrial diameter
\end{abstract}


Copyright $\odot 2017$ by authors and Scientific Research Publishing Inc. This work is licensed under the Creative Commons Attribution International License (CC BY 4.0).

http://creativecommons.org/licenses/by/4.0/
$(\mathrm{P}=0.001)$ were observed after 12 weeks. In addition, diastolic blood pressure $(\mathrm{P}=0.027)$ and resting heart rate $(\mathrm{P}<0.001)$ were reduced after ST. In the CO group, no significant changes were observed in the examined variables after 12 weeks. Despite within group changes in the ST group, no significant differences were observed after 12 weeks between groups in echocardiographic variables, peak oxygen consumption, blood pressure and peripheral microvascular function. Conclusion: In men with prostate cancer receiving ADT, echocardiography showed no abnormalities in cardiac structure and function. Twelve weeks of ST failed to elicit significant cardiovascular adaptations and ADT may blunt cardiovascular adaptations to short-term exercise training.

\section{Keywords}

Prostate Cancer, Exercise, Rehabilitation, Cardiovascular

\section{Introduction}

Androgen deprivation therapy (ADT) is a cornerstone in prostate cancer (PCa) management that prolongs PCa-free and overall survival. However, ADT is associated with increased risk of cardiovascular disease (CVD) and risk factors such as adiposity, type 2 diabetes, increased circulating lipid levels and augmented central aortic stiffness, along with reduction of muscle strength and physical capacity [1]-[7]. Limited experimental evidence has also suggested that ADT can influence cardiac function and in rats ADT is associated with left ventricular (LV) dysfunction, which can be ameliorated by exercise training (EX) [8]. Exercise training level is inversely related to long term PCa survival and has been documented as a feasible, safe and effective means for improvement of fitness, body composition and quality of life in PCa patients undergoing ADT [4] [6] [9] [10] [11] [12]. Soccer training (ST) is akin to high intensity interval training and while effects of ST have as yet not been examined in patients undergoing ADT, we have found that small-sided recreational ST elicits cardiovascular adaptations and marked improvements of physical capacity in, for example, elderly healthy men, and men with hypertension or type 2 diabetes [13] [14] [15] [16] [17]. Importantly, ST is associated with positive psychosocial interactions that augment social capital, improve quality of life and contain rational and action-oriented elements that have been requested by male cancer patients and is likely to improve long-term adherence to EX [18] [19].

In view of the increased risk of CVD in patients with PCa undergoing ADT, it is important to determine if ADT is associated with cardiac abnormalities and effects on cardiac adaptations to EX. We are, however, not aware of reports on cardiac structure and function in patients with PCa undergoing ADT, and it is unknown if EX can elicit similar cardiac adaptations in these patients as has been observed in other subjects [4] [6] [9] [10] [11] [12] [14] [16] [20] [21] [22]. Comprehensive echocardiography with tissue Doppler imaging (TDI) and 


\section{Excluded (n)}

No time1

Disliked the intervention1

Lymph edema1

Pre-existing hernia scheduled for operation during the intervention 1

Musculoskeletal injuries5 speckle tracking analysis of 2D global systolic longitudinal strain (GLS) is a sensitive tool to detect subclinical cardiac dysfunction [23] [24] [25] [26]. Therefore, the purpose of the present study was to examine in men with PCa undergoing ADT: 1) cardiovascular structure and function by comprehensive echocardiography, and 2) cardiovascular adaptations in response to a short-term ST intervention.

\section{Methods}

\subsection{Patients and Study Design}

From March 2012 to December 2013, patients with histologically confirmed advanced or locally advanced PCa were recruited in Copenhagen Denmark. Study flow is presented in Figure 1 and the full study design was recently reported [27]. Fifty-seven patients were found to be eligible for baseline testing and were randomized 1:1 to a 12 week structured EX program consisting of ST (ST group $\mathrm{n}=29)$ or a usual care control group (CO; $\mathrm{n}=28)$. Forty-three patients completed the study (ST group $n=20)$ and usual care control group $(\mathrm{CO} ; \mathrm{n}=23$ ). The study was approved by the Danish National Committee and all participants provided written informed consent. EX was performed as small-sided (4vs. 4; 5 vs. 5; or 6 vs. 6) recreational ST two-three times per week for 12 weeks. The patients in the $\mathrm{CO}$ group were encouraged to maintain their baseline physical activity level during the study. Clinicaltrials.gov identifier number NCT01711892.

\subsection{Cardiovascular Function and Fitness}

All subjects were examined at baseline and after 12 weeks by comprehensive transthoracic echocardiography as described previously [27]. Measurements of cardiac structure and function were obtained by standard 2D echocardiography and LVEF $<45 \%$ and peak early diastolic velocity $E^{\prime}<9 \mathrm{~cm} / \mathrm{s}$ was considered as

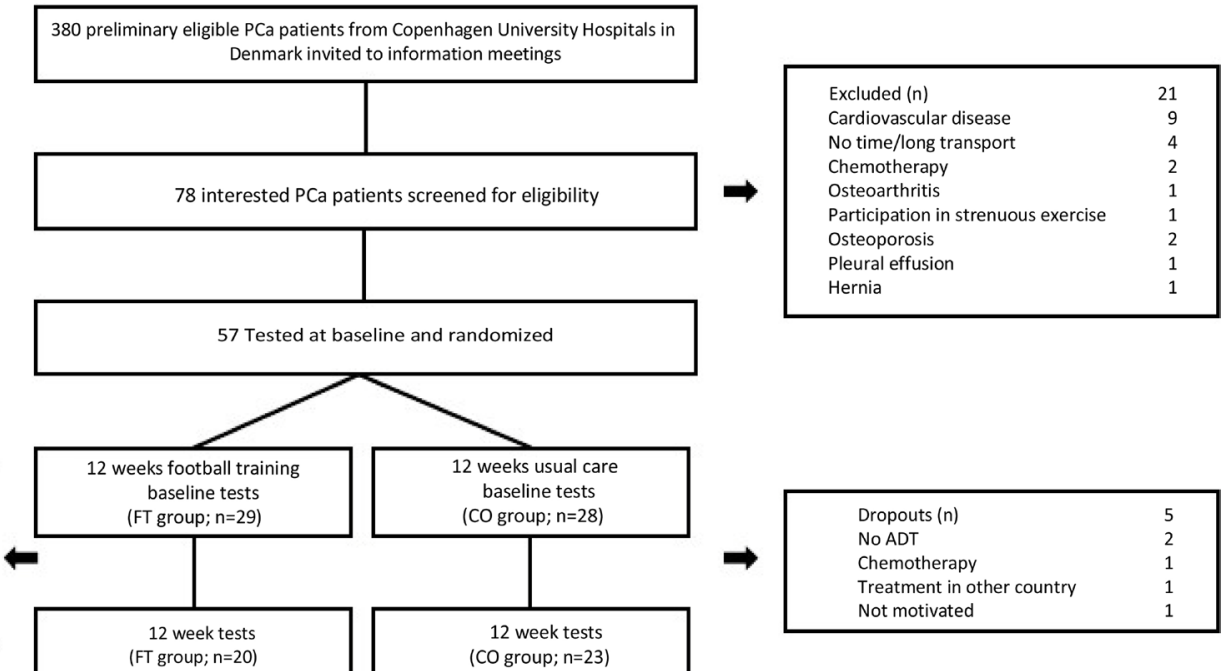

Figure 1. Consort diagram with the recruitment process for the study. PCa, prostate cancer; ADT, Androgen deprivation therapy; FT, football training; CO, control. 
LV systolic dysfunction and LV diastolic dysfunction, respectively [28] [29] [30]. Tissue Doppler imaging including measurements of LV longitudinal systolic shortening (LVdisplacement) by tissue tracking using 2D colour tissue Doppler and 2D longitudinal global strain (GLS) by speckle tracking were obtained as described previously [31] [32]. Peripheral arterial tonometry measurements of the reactive hyperaemic index (RHI) and the augmentation index adjusted to a heart rate of $75 \mathrm{bpm}$ (AI) were measured using the EndoPat-2000 ${ }^{\circledR}$ (Itamar Medical Ltd., Caesarea, Israel) as described previously [14] [27] [33]. Blood pressure (BP) and resting heart rate (RHR) were measured simultaneously 6 times and averaged. Height was measured by a stadiometer, body weight on a digital platform scale and body mass index $\left[\mathrm{kg}\left[\mathrm{m}^{2}\right]^{-1}\right]$ was calculated. All patients completed an incremental test on a bike and peak oxygen uptake (VO2peak) was determined by pulmonary gas exchange measurements and maximal heart rate (HRmax) was determined.

\subsection{Statistics}

To detect a difference of $0.25 \pm 0.26$ in mean diastolic E/A ratio and $1.8 \pm 1.5 \mathrm{~cm}$ $\mathrm{s}^{-1}$ in mean peak early diastolic velocity (E') reported between elderly healthy untrained men who participated in a ST intervention and a control group observed in a recent study from our group [16], twelve and (E') and eighteen (E/A) patients in each group were found to be required to detect a similar change with a power of $80 \%$ and an alpha level of 0.05 . However, the study was multidisciplinary with several other endpoints and the actual power calculation was therefore based on group differences in lean body mass as reported previously [16] [27]. Data were analyzed with $S_{A S}{ }^{\circledR}$ version 9.3. Data were tested for normal distributions and analyzed with descriptive statistic, t-tests, Fishers exact tests, linear associations and analyses of covariance (ANCOVA). All data are presented as absolute means \pm standard deviations (SDs) or median (range) (Table 1). All data analyses were based on patients who completed the study (ST group; $\mathrm{n}=20$, and CO group; $\mathrm{n}=23$ ) (Figure 1). The significance level was set at 0.05 .

\section{Results}

\subsection{Patient Characteristics and Study Adherence}

The two groups were well balanced except for a lower diastolic BP in the CO group $(\mathrm{P}=0.020)$ (Table 1$)$. In the ST and CO groups, 9 out of $29(30 \%)$ and 5 out of 28 (18\%), respectively, did not complete the full intervention period and consequently 43 patients were therefore included in the analyses. The study flowchart and reasons for not completing the study are listed in Figure 1.

\subsection{Baseline Echocardiography}

At baseline, LA diameter was $37 \pm 5 \mathrm{~mm}, \mathrm{LV}$ mass index was $89.1 \pm 16.3 \mathrm{~g} \mathrm{~m}^{-2}$, LVEF was $58 \% \pm 6 \%$, and GLS was $-19.0 \pm 3.9$, respectively. No patient had LVEF $<45 \%$ and 3 of 43 patients (7\%) had LVEF $<50 \%$. LV diastolic dysfunction 
Table 1. Baseline characteristics of the participants in the football training (FT) and control (CO) groups. Results are means \pm SDs, median [range] or number of participants (\%). BMI, body mass index; BP, blood pressure; ADT, androgen deprivation therapy; LNRH, luteinizing hormone-releasing hormone.

\begin{tabular}{|c|c|c|c|c|c|}
\hline & \multicolumn{2}{|c|}{ FT group $(n=20)$} & \multicolumn{2}{|c|}{ CO group $(n=23)$} & \multirow{2}{*}{$P$-values } \\
\hline & Mean \pm SD & Median [range] & Mean \pm SD & Median [range] & \\
\hline Age (yrs) & $68.6 \pm 7.9$ & $72[44-75]$ & $67.7 \pm 4.7$ & $68[55-75]$ & 0.64 \\
\hline Height $(\mathrm{cm})$ & $178 \pm 6$ & $175[169-190]$ & $180 \pm 6$ & $180[172-196]$ & 0.16 \\
\hline Weight (kg) & $85.1 \pm 11.5$ & $81[73-112]$ & $89.7 \pm 9.9$ & $90[72-108]$ & 0.17 \\
\hline BMI $\left(\mathrm{kg} \mathrm{m}^{-2}\right)$ & $27.0 \pm 3.0$ & $27[20-35]$ & $27.6 \pm 2.4$ & $28[23-32]$ & 0.46 \\
\hline Systolic BP (mmHg) & $131 \pm 13$ & $129[109-163]$ & $127 \pm 13$ & $125[102-160]$ & 0.34 \\
\hline Diastolic BP (mmHg) & $81 \pm 8$ & $80[65-105]$ & $76 \pm 7$ & $76[65-90]$ & 0.02 \\
\hline \multicolumn{6}{|l|}{ Prostate cancer specifics } \\
\hline Time from diagnosis (months) & $42 \pm 44$ & $28[10-160]$ & $46 \pm 34$ & $37[12-167]$ & 0.77 \\
\hline ADT treatment (months) & $28 \pm 21$ & $60[10-104]$ & $33 \pm 16$ & $30[10-65]$ & 0.38 \\
\hline Gleason score & $8 \pm 1$ & $8[6-124]$ & $8 \pm 1$ & $8[6-9]$ & 0.84 \\
\hline Surgical therapy (\% of subjects) & $14 / 20(70 \%)$ & - & $20 / 23(87 \%)$ & - & 0.26 \\
\hline Radiation therapy (\% of subjects) & $10 / 20(50 \%)$ & - & $9 / 23(39 \%)$ & - & 0.68 \\
\hline \multicolumn{6}{|l|}{ Metastases (\% of subjects) } \\
\hline No metastases & $12 / 20(60 \%)$ & - & $13 / 23(57 \%)$ & - & 0.93 \\
\hline Lymph node metastases & $3 / 20(15 \%)$ & - & $7 / 23(30 \%)$ & - & 0.29 \\
\hline Bone metastases & $5 / 20(25 \%)$ & - & $3 / 23(13 \%)$ & - & 0.44 \\
\hline \multicolumn{6}{|l|}{ Medication } \\
\hline LNRH agonist & $20 / 20(100 \%)$ & - & $23 / 23(100 \%)$ & - & $1: 00$ \\
\hline Androgen antagonist & $1 / 20(5 \%)$ & - & $5 / 23(22 \%)$ & - & 0.70 \\
\hline Antihypertensive medication & $9 / 20(45 \%)$ & - & $13 / 23(57 \%)$ & - & 0.64 \\
\hline Statin & $3 / 20(15 \%)$ & - & $1 / 23(4 \%)$ & - & 0.61 \\
\hline Calcium D vitamin supplement & $13 / 20(65 \%)$ & - & $15 / 23(65 \%)$ & - & 0.76 \\
\hline
\end{tabular}

was present in $30 \%$ of all patients, with $85 \%$ of these classified as mild and $15 \%$ as moderate diastolic dysfunction. E/A ratio and E' were inversely associated with age $(\mathrm{r}=-0.56, \mathrm{P}=0.0001$ and $\mathrm{r}=-0.38, \mathrm{P}=0.012$, respectively).

\subsection{ST Intervention Characteristics}

In the ST group, a total of 28 ST sessions were performed and on average $23 \pm 4$ $(82 \% \pm 16 \%)$ were completed. HRmax was $164 \pm 14 \mathrm{bpm}$ and ST was performed with an average heart rate of $138 \pm 14 \mathrm{bpm}(84 \% \pm 4 \%$ of HRmax). Specifically, $5 \%$ of the total ST time during the intervention was performed at heart rates < $70 \%$ of HRmax, and $20 \%$ between $70 \%-80 \%, 50 \%$ between $80 \%-90 \%, 20 \%$ between $90 \%$ - 95\% and $4 \%$ between $95 \%$ - 100\% of HRmax, respectively.

\subsection{Effects of ST}

\subsubsection{Cardiac Structure and Function}

During the 12 week intervention, LA diameter $(\mathrm{P}=0.001)$ increased in the ST 
group and this change was inversely associated with baseline values $(\mathrm{P}<0.001)$. No within or between group differences were observed for other geometric measures of cardiac structure (Table 2).

Twelve-weeks of ST did not induce any within or between group differences in LV or RV systolic function including TDI measurements and GLS (Table 2 and Table 3). After 12 weeks, diastolic variables including $\mathrm{E} / \mathrm{A}$ ratio $(\mathrm{P}=0.030)$, peak early diastolic velocity $\left(\mathrm{E}^{\prime}\right)(\mathrm{P}=0.016)$ and E'ColourTDI $(\mathrm{P}=0.040) \mathrm{im}$ proved in the ST group and these changes were inversely associated with baseline values $(\mathrm{P}<0.01)$. No changes in diastolic variables were observed in the $\mathrm{CO}$ group or between groups during the 12 week intervention.

\subsection{2. $\mathrm{VO}_{2}$ Peak, BP, RHR, and Peripheral Microvascular Function}

In the ST group, diastolic $\mathrm{BP}(\mathrm{P}=0.027)$ and RHR $(\mathrm{P}<0.001)$ were reduced after 12 weeks with no between group differences compared to CO (Table 4).

Table 2. Standard echocardiographic values at baseline and after 12 weeks in the football training (FT) and control (CO) groups. LVEDD, Left ventricular end-diastolic diameter; LVEDV, LV end-diastolic volume; IVSd, interventricular septal wall thickness; PWT, posterior wall thickness; LV mass index, LV mass adjusted for body surface area; LVEF, LV ejection fraction; MV E velocity, early transmitral inflow; MV A velocity, late transmitral inflow; LA, left atrium. Absolute values are presented as means (SDs) and changes as means (\%95 confidence intervals).

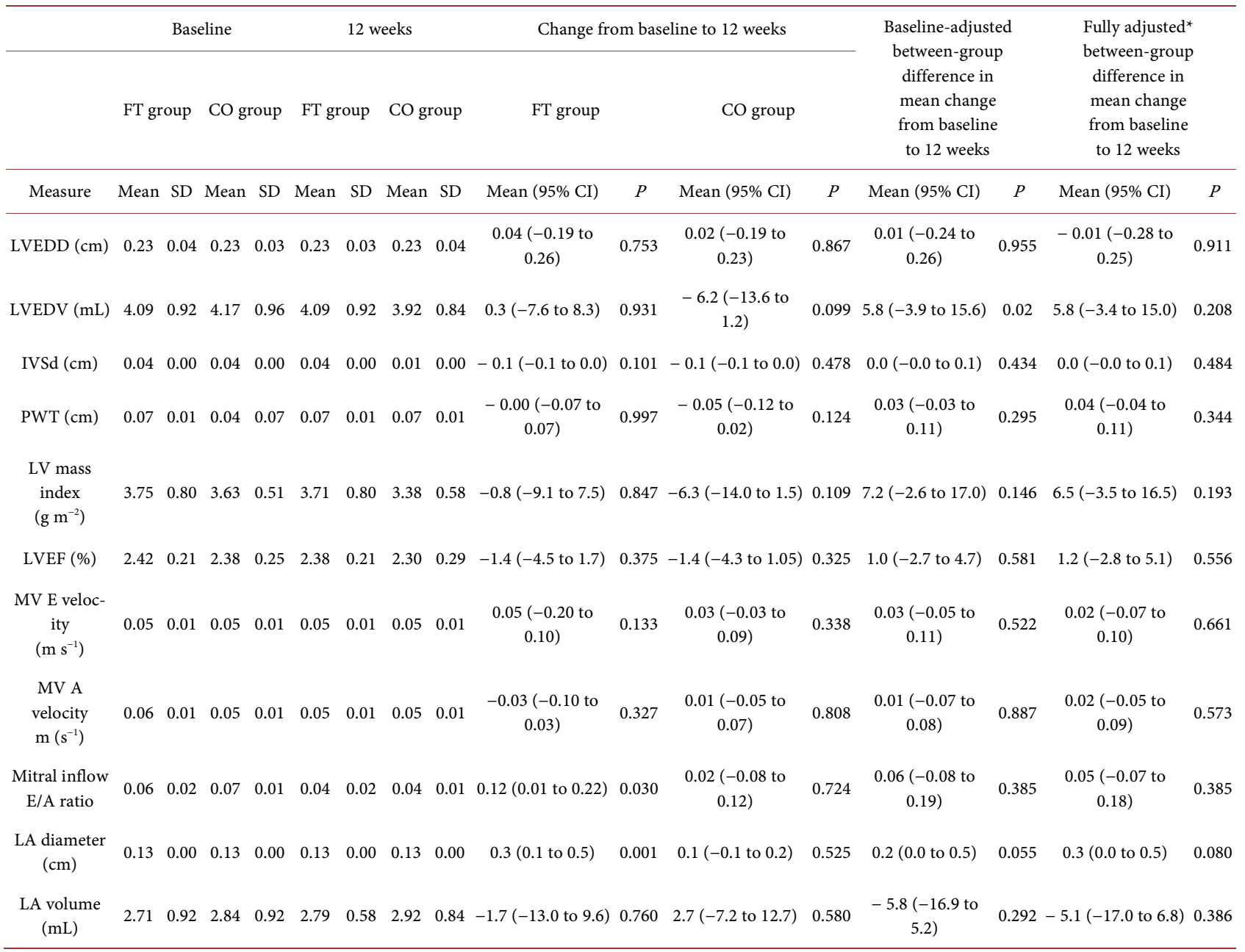


Table 3. Tissue Doppler imaging echocardiography values at baseline and after 12 weeks in the football training (FT) and control (CO) groups. S', peak systolic velocity; E', peak early diastolic velocity; A', peak late diastolic velocity; S' ${ }_{\text {TDIcolor }}$, peak systolic velocity; E' ${ }_{\text {TDIcolor }}$, peak early diastolic velocity; $\mathrm{A}^{\prime}$ TDIcolor, peak late diastolic velocity; LV displacement, LV systolic longitudinal shortening; GLS, 2D global longitudinal systolic strain. Absolute values are presented as means (SDs) and changes as means (\%95 confidence intervals).

\begin{tabular}{|c|c|c|c|c|c|c|c|c|c|c|c|c|c|c|c|c|}
\hline \multirow[b]{3}{*}{ Measure } & \multicolumn{4}{|c|}{ Baseline } & \multicolumn{4}{|c|}{12 weeks } & \multicolumn{4}{|c|}{ Change from baseline to 12 weeks } & \multicolumn{2}{|c|}{$\begin{array}{l}\text { Baseline-adjusted } \\
\text { between-group } \\
\text { difference } \\
\text { in mean change from } \\
\text { baseline to } 12 \text { weeks }\end{array}$} & \multicolumn{2}{|c|}{$\begin{array}{c}\text { Fully adjusted } \\
\text { between-group } \\
\text { difference in mean } \\
\text { change from baseline to } \\
12 \text { weeks }\end{array}$} \\
\hline & \multicolumn{2}{|c|}{ FT group } & \multicolumn{2}{|c|}{$\mathrm{CO}$ group } & \multicolumn{2}{|c|}{ FT group } & \multicolumn{2}{|c|}{ CO group } & \multicolumn{2}{|l|}{ FT group } & \multicolumn{2}{|l|}{ CO group } & \multicolumn{2}{|l|}{ FT group } & \multicolumn{2}{|l|}{ CO group } \\
\hline & Mean & $\mathrm{SD}$ & Mean & $\mathrm{SD}$ & Mean & SD & Mean & SD & Mean $(95 \% \mathrm{CI})$ & $P$ & Mean $(95 \% \mathrm{CI})$ & $P$ & Mean $(95 \% \mathrm{CI})$ & $P$ & Mean $(95 \%$ CI $)$ & $P$ \\
\hline$S^{\prime}\left(\mathrm{cm} \mathrm{s}^{-1}\right)$ & 8.09 & 1.08 & 8.08 & 1.05 & 8.06 & 1.03 & 9.00 & 1.04 & $-0.1(-0.7$ to 0.5$)$ & 0.740 & $0.2(-0.4$ to 0.8$)$ & 0.494 & $-0.3(-1.1$ to 0.4$)$ & 0.322 & $-0.3(-1.1$ to 0.4$)$ & 0.377 \\
\hline $\mathrm{E}^{\prime}\left(\mathrm{cm} \mathrm{s}^{-1}\right)$ & 8.00 & 2.07 & 9.04 & 2.00 & 9.02 & 2.01 & 10.01 & 1.06 & $1.2(0.0$ to 2.2$)$ & 0.016 & $0.6(-0.3$ to 1.5$)$ & 0.208 & $-0.3(-1.3$ to 0.7$)$ & 0.582 & $-0.2(-1.4$ to 0.8$)$ & 0.604 \\
\hline $\mathrm{A}^{\prime}\left(\mathrm{cm} \mathrm{s}^{-1}\right)$ & 12.05 & 1.08 & 11.09 & 2.01 & 11.04 & 2.00 & 11.02 & 2.05 & $-0.9(-1.6$ to -0.2$)$ & 0.012 & $-0.6(-1.3$ to 0.0$)$ & 0.063 & $-0.2(-1.2$ to 0.7$)$ & 0.643 & $-0.1(-1.1$ to 0.8$)$ & 0.779 \\
\hline $\begin{array}{l}\mathrm{S}^{\prime} \text { color }_{\mathrm{TDI}} \\
\left(\mathrm{cm} \mathrm{s}^{-1}\right)\end{array}$ & 5.08 & 1.02 & 5.05 & 1.00 & 5.06 & 1.01 & 5.05 & 1.02 & $-0.2(-0.5$ to 0.3$)$ & 0.446 & $0.0(-0.34$ to 0.41$)$ & 0.856 & $-0.1(-0.6$ to 0.4$)$ & 0.750 & $-0.1(-0.6$ to 0.46$)$ & 0.740 \\
\hline $\begin{array}{l}\mathrm{A}^{\prime} \text { Color } \\
\left(\mathrm{cm} \mathrm{s}^{-1}\right)\end{array}$ & 7.07 & 1.04 & 7.02 & 2.02 & 7.14 & 1.51 & 6.05 & 2.01 & $-0.5(-1.2$ to 0.2$)$ & 0.128 & $-0.8(1.5$ to 0.1$)$ & 0.027 & $-0.4(-1.3$ to 0.5$)$ & 0.344 & $-0.5(-1.4$ to 0.4$)$ & 0.292 \\
\hline $\begin{array}{c}\text { LV } \\
\text { displacem } \\
\text { ent }(\mathrm{mm})\end{array}$ & 10.09 & 1.04 & 10.05 & 1.07 & 10.06 & 2.01 & 9.09 & 2.04 & $-0.2(-1.1$ to 0.7$)$ & 0.592 & $-0.7(-1.5$ to 0.2$)$ & 0.114 & $0.5(-0.7$ to 1.8$)$ & 0.368 & $0.7(-0.5$ to 1.9$)$ & 0.256 \\
\hline $\begin{array}{c}\text { Global } \\
\text { strain (\%) }\end{array}$ & -19.3 & 2.02 & -18.2 & 5.07 & -20.7 & 1.07 & -19.1 & 1.08 & $-0.4(-3.4$ to 2.5$)$ & 0.778 & $-1.2(-4.0$ to 1.6$)$ & 0.389 & $\begin{array}{c}-0.95(-2.5 \text { to } \\
0.6)\end{array}$ & 0.220 & $-0.4(-2.3$ to 1.5$)$ & 0.647 \\
\hline
\end{tabular}

Table 4. Peak oxygen consumption $\left(\mathrm{VO}_{2}\right.$ peak), blood pressure (BP), resting heart rate (RHR) and peripheral microvascular function at baseline and after 12 weeks in the football training (FT) and control (CO) groups. RHI, reactive hyperemic index; AI, augmentation index. Absolute values are presented as means (SDs) and changes as means (\%95 confidence intervals).

\begin{tabular}{|c|c|c|c|c|c|c|c|c|c|c|c|c|c|c|c|c|}
\hline & & Base & eline & & & & 12 weeks & & Change fr & from ba & seline to 12 we & eeks & \multicolumn{2}{|c|}{$\begin{array}{l}\text { Baseline-adjusted } \\
\text { between-group } \\
\text { difference in } \\
\text { mean change } \\
\text { from baseline to } \\
12 \text { weeks }\end{array}$} & \multicolumn{2}{|c|}{$\begin{array}{c}\text { Fully adjusted }{ }^{*} \\
\text { between-group } \\
\text { difference in mean } \\
\text { change from } \\
\text { baseline to } 12 \text { weeks }\end{array}$} \\
\hline & \multicolumn{2}{|c|}{ FT group } & \multicolumn{2}{|c|}{$\mathrm{CO}$ group } & \multicolumn{2}{|c|}{ FT group } & \multicolumn{2}{|c|}{$\mathrm{CO}$ group } & \multicolumn{2}{|c|}{ FT group } & \multicolumn{2}{|c|}{ CO group } & \multicolumn{2}{|c|}{ FT group } & \multicolumn{2}{|c|}{$\mathrm{CO}$ group } \\
\hline Measure & Mean & SD & Mean & $\mathrm{SD}$ & Mean & SD & Mean & SD & $\begin{array}{c}\text { Mean }(95 \% \\
\text { CI })\end{array}$ & $P$ & $\begin{array}{c}\text { Mean }(95 \% \\
\mathrm{CI})\end{array}$ & $P$ & $\begin{array}{c}\text { Mean } \\
(95 \% \mathrm{CI})\end{array}$ & $P$ & $\begin{array}{c}\text { Mean }(95 \% \\
\text { CI })\end{array}$ & $P$ \\
\hline $\begin{array}{l}\mathrm{VO}_{2} \text { peak } \\
\left(\mathrm{L} \mathrm{min}^{-1}\right)\end{array}$ & 2.32 & 0.34 & 2.41 & 0.39 & 2.38 & 0.37 & 2.43 & 0.37 & $\begin{array}{l}0.06(-0.03 \\
\text { to } 0.15)\end{array}$ & 0.162 & $\begin{array}{l}0.02(-0.06 \\
\quad \text { to } 0.10)\end{array}$ & 0.618 & $\begin{array}{l}0.03(-0.09 \\
\quad \text { to } 0.15)\end{array}$ & 0.633 & $\begin{array}{l}0.01(-0.09 \\
\text { to } 0.11)\end{array}$ & 0.817 \\
\hline $\begin{array}{c}\text { Systolic } \\
\text { BP } \\
(\mathrm{mmHg})\end{array}$ & 131.00 .00 & 13.04 & 127.03 .00 & 13.04 & 128.04 .00 & 15.09 & 128.07 .00 & 15.09 & $\begin{array}{c}-2.6(-6.9 \\
\text { to } 1.8)\end{array}$ & 0.236 & $\begin{array}{c}1.4(-2.5 \text { to } \\
5.4)\end{array}$ & 0.48 & $\begin{array}{c}-3.6(-9.6 \\
\text { to } 2.3)\end{array}$ & 0.225 & $\begin{array}{c}-2.4(-8.1 \text { to } \\
3.3)\end{array}$ & 0.402 \\
\hline $\begin{array}{l}\text { RHR } \\
\text { (bpm) }\end{array}$ & 60.03 .00 & 11.04 & 58.00 .00 & 8.03 & 56.02 .00 & 9.09 & 56.04 .00 & 8.09 & $\begin{array}{c}-4.1(-6.4 \\
\text { to }-1.8)\end{array}$ & 0.000 & $\begin{array}{c}-1.5(-3.6 \text { to } \\
0.5)\end{array}$ & 0.143 & $\begin{array}{c}-2.2(-5.1 \\
\text { to } 0.8)\end{array}$ & 0.141 & $\begin{array}{c}-2.1(-5.0 \text { to } \\
0.7)\end{array}$ & 0.141 \\
\hline RHI & 2.35 & 0.047 & 2.19 & 0.04 & 2.29 & 0.57 & 2.30 & 0.045138889 & $\begin{array}{c}-0.10(-0.41 \\
\text { to } 0.31)\end{array}$ & 0.716 & $\begin{array}{c}0.11(-0.22 \\
\text { to } 0.51)\end{array}$ & 0.394 & $\begin{array}{c}-0.12(-0.5 \\
2 \text { to } 0.31)\end{array}$ & 0.699 & $\begin{array}{c}-0.10(-0.50 \\
\text { to } 0.32)\end{array}$ & 0.722 \\
\hline $\mathrm{AI}$ & 10.03 & 14.01 & 8.08 & 10.06 & 10.04 & 14.01 & 9.06 & 15.00 & $\begin{array}{c}0.7(-3.3 \text { to } \\
4.7)\end{array}$ & 0.718 & $\begin{array}{c}0.1(-3.8 \text { to } \\
4.0)\end{array}$ & 0.964 & $\begin{array}{c}0.6(-5.0 \\
\text { to } 6.3)\end{array}$ & 0.819 & $\begin{array}{c}-0.8(-6.5 \text { to } \\
5.0)\end{array}$ & 0.788 \\
\hline
\end{tabular}


During the 12 week intervention, no within or between group changes were observed for VO2 peak, systolic BP, RHI and AI.

\subsubsection{Adverse Events}

In the ST group, 2 patients sustained fibular bone fractures during ST session 1 and 16, respectively, and both cases were solo injuries unrelated to tackles or physical contact with other participants. Three patients sustained other injuries, including a partial Achilles tendon rupture $(n=1)$, a sprained ankle $(n=1)$, and a strained muscle $(n=1)$, respectively. All 5 patients fully recovered from these injuries after conservative treatment but were excluded from all the analyses (Figure 1).

\section{Discussion}

To our knowledge, this is the first study to evaluate cardiac structure and function in PCa patients receiving ADT by comprehensive echocardiography before and after a short-term EX intervention. At baseline, considerable cardiac abnormalities were not observed. After 12 weeks, patients randomized to ST displayed significant changes of LA diameter and LV diastolic function in the per-protocol analysis, but no differences were observed in echocardiographic variables between the ST and CO groups. The results suggest that ADT does not have major effects on echocardiographic variables, but may blunt cardiac adaptations to EX.

In men with PCa, ADT is associated with an increased risk of CVD and it is therefore important to determine if cardiac structure and function is attenuated in these patients in absence of overt CVD [3] [7]. Prior to randomization, no considerable structural cardiac abnormality e.g. LV hypertrophy (LVH), was observed in our patients despite that $\sim 50 \%$ of patients received antihypertensive medication, which is similar to the percentage of age-matched men treated with antihypertensive agents in the general population [34]. An elevated blood pressure is associated with increased LV afterload which may induce LVH and absence of LVH in our patients is likely to be related to adequate blood pressure control owing to previous long-term medical surveillance associated with ADT. It is, however, interesting that LVH was actually less prevalent in our hypertensive patients compared to hypertensive patients in general and it is possible that ADT may counteract development of LVH in these patients [35] [36]. We also observed a preserved LV systolic function and TDI-derived peak systolic velocity (S'ColourTDI)), and GLS values in our patients were within the normal range, which clearly suggests that subclinical myocardial dysfunction at rest is a rare finding in PCa patients receiving ADT [23] [37]. Aging is associated with reduced resting LV diastolic function mainly because of reduced LV compliance and relaxation [38]. Along this line, we observed lower LV diastolic values (E/A ratio, E'and E' TDIcolour) in older patients and the prevalence of LV diastolic dysfunction was $30 \%$ in our study population with a mean age of 68 years. These findings correspond to the prevalence of LV diastolic function in the general 
population and suggest that $\mathrm{ADT}$ does not accelerate the age-related decline in diastolic function [23] [39].

During the last few years, studies of recreational small-sided ST and other types of EX have demonstrated marked effects on cardiac structure and LV function [14] [16] [22] [40] [41] [42]. A growing body of evidence has also suggested that EX is a powerful intervention to mitigate ADT-related reductions of musculoskeletal and cardiorespiratory functions, but as yet, no study has evaluated the effects of EX on cardiac structure and function in patients receiving ADT [4] [6] [9] [11] [12]. In rodents, chemical orchiectomy has been associated with LV systolic dysfunction which was attenuated by EX [8]. Surprisingly, the present study failed to demonstrate significant changes in cardiac structure or function as measured by comprehensive echocardiography after 12 weeks of ST in patients receiving $\mathrm{ADT}$ as compared to controls, even though such intervention has previously been associated with substantial changes of echocardiographic variables in healthy men and men with hypertension or diabetes [14] [16] [41]. In the ST group, we observed an augmented LV diastolic function and increased LA size after 12 weeks, but these changes were influenced by lower baseline values and were not significantly different from the response in the $\mathrm{CO}$ group.

Notably, improvements of $\mathrm{VO}_{2}$ peak were also absent after 12 weeks of ST in our study and it is possible that this attenuated response as compared to increased $\mathrm{VO}_{2}$ peak observed after ST in other patient subsets e.g. men with hypertension or diabetes, was related to the lack of changes in cardiac structure and function [14] [17]. On the other hand, other types of EX training e.g. cycling, jogging or combined aerobic and resistance training have been found to improve aerobic fitness in many, but not all, studies of men with PCa receiving $\mathrm{ADT}$, whereas absence of between group differences in BP after EX in our patients is in line with the findings of others [4] [6] [9] [10] [11] [12] [43]. The EX training modality is likely a major determinant of the improvement of $\mathrm{VO}_{2}$ peak and cardiac adaptations and emerging evidence has indicated that in this regard, high-intensity interval training may be more efficient than moderate-intensity continuous EX e.g. in previously sedentary subjects or patients with heart failure or coronary artery disease, respectively [20] [21] [44]. Indeed, we have found that ST, which is akin to high-intensity interval training, was more effective than running to achieve increased $\mathrm{VO}_{2}$ peak and other cardiovascular adaptations in sedentary women [22]. In addition to our observations in men with hypertension and diabetes, we have also observed marked cardiovascular effects including increased $\mathrm{VO}_{2}$ peak after ST in healthy untrained 65 - 75 year-old men without soccer experience and in veteran soccer players with life-long participation in ST [14] [17] [42]. In the present study, men with PCa receiving ADT achieved similar high heart rates during ST as we have observed in other subjects reported in our previous studies, and the absence of changes in $\mathrm{VO}_{2}$ peak and cardiac structure and function, respectively, therefore clearly suggest that $\mathrm{ADT}$ can counte- 
ract favourable cardiovascular effects of high-intensity interval training.

We measured microvascular endothelial function by use of peripheral arterial tonometry, which is a noninvasive, automated and operator-independent method that is easy to perform compared to other methods used to evaluate endothelial function e.g. invasive protocols or ultrasound measurements of flow-mediated vasodilation of the brachial artery [16] [33]. Microvascular endothelial function has been suggested to be more sensitive to cardiometabolic risk factors e.g. body mass index and diabetes mellitus, and may display abnormalities dependent on such risk factors earlier than measures of conduit artery endothelial function [33]. Importantly, endothelial dysfunction measured by these noninvasive techniques is an independent risk factor of CVD and physical activity can attenuate the general age-related decline in endothelial function and nitric oxide bioavailability [45] [46]. While we are not aware of previous studies of microvascular endothelial function in this setting, EX was recently associated with improved endothelial function measured by flow-mediated brachial artery vasodilation in PCa patients not receiving ADT [47]. In our study, however, 12 weeks of ST did not elicit significant changes in peripheral microvascular function. This is finding is in line with results of other studies with peripheral arterial tonometry after ST and other types of EX and, taken together, these data suggest that microvascular endothelial function is not augmented by short-term EX [14] [48] [49].

In a recent publication from the present study cohort, ST was found to be experienced by patients as a feasible and enjoyable exercise modality that was associated with a sense of regained control over their health and promotion of a mutually caring behaviour between subjects [16] [50]. Although we observed a number of musculoskeletal injuries, such injuries must be weighed against the psychological benefits and the detrimental effects of physical inactivity and consequent morbidity and mortality.

A number of limitations apply to the present study. The study was small-scale, it only examined effects of ST [not other EX modalities] and the study population was exposed to selection bias e.g. the intervention preferentially attracted interested patients capable of performing exercise training. The lack of a control group of PCa patients not receiving ADT, measurements of conduit artery endothelial function and assessment by stress echocardiography are also among the limitations of the study. Moreover, long-terms effects and effects of ST on clinical endpoints were not examined.

\section{Conclusion}

In men with $\mathrm{PCa}$ receiving $\mathrm{ADT}$, considerable echocardiographic abnormalities at rest were not observed, whereas 12 weeks of ST failed to elicit significant cardiovascular adaptations. The results suggest that ADT is not associated with significant effects on cardiac structure and function, but that such treatment may blunt cardiovascular adaptations to short-term exercise training. 


\section{Acknowledgements}

We sincerely thank statistician Henrik Steen Andersen for outstanding statistical support and Jens Jung Nielsen for great practical support. J.F.S had full access to all the data in the study and takes responsibility for the integrity of the data and the accuracy of the data analysis.

\section{Conflict of Interest}

None Declared.

\section{Funding}

The study was funded by The Beckett-Foundation, Tryg-fonden, Preben \& Anna Simonsen's Foundation, The Danish Cancer Society and The Novo Nordisk Foundation.

\section{References}

[1] Nilsson, P.M., Nilsson, J.A. and Berglund, G. (2006) Population-Attributable Risk of Coronary Heart Disease Risk Factors during Long-Term Follow-Up: The Malmo Preventive Project. Journal of Internal Medicine, 260, 134-141. https://doi.org/10.1111/j.1365-2796.2006.01671.x

[2] Levine, G.N., D’Amico, A.V., Berger, P., et al. (2010) Androgen-Deprivation Therapy in Prostate Cancer and Cardiovascular Risk: A Science Advisory from the American Heart Association, American Cancer Society, and American Urological Association: Endorsed by the American Society for Radiation Oncology. Circulation, 121, 833-840. https://doi.org/10.1161/CIRCULATIONAHA.109.192695

[3] Jespersen, C.G., Norgaard, M. and Borre, M. (2014) Androgen-Deprivation Therapy in Treatment of Prostate Cancer and Risk of Myocardial Infarction and Stroke: A Nationwide Danish Population-Based Cohort Study. European Urology, 65, 704-709. https://doi.org/10.1016/j.eururo.2013.02.002

[4] Galvao, D.A., Taaffe, D.R., Spry, N., et al. (2010) Combined Resistance and Aerobic Exercise Program Reverses Muscle Loss in Men Undergoing Androgen Suppression Therapy for Prostate Cancer without Bone Metastases: A Randomized Controlled Trial. Journal of Clinical Oncology, 28, 340-347. https://doi.org/10.1200/JCO.2009.23.2488

[5] Dockery, F., Bulpitt, C.J., Agarwal, S., et al. (2003) Testosterone Suppression in Men with Prostate Cancer Leads to an Increase in Arterial Stiffness and Hyperinsulinaemia. Clinical Science (London), 104, 195-201. https://doi.org/10.1042/cs1040195

[6] Gardner, J.R., Livingston, P.M. and Fraser, S.F. (2014) Effects of Exercise on Treatment-Related Adverse Effects for Patients with Prostate Cancer Receiving Androgen-Deprivation Therapy: A Systematic Review. Journal of Clinical Oncology, 32, 335-346. https://doi.org/10.1200/JCO.2013.49.5523

[7] Saigal, C.S., Gore, J.L., Krupski, T.L., et al. (2007) Androgen Deprivation Therapy Increases Cardiovascular Morbidity in Men with Prostate Cancer. Cancer, 110, 1493-1500. https://doi.org/10.1002/cncr.22933

[8] Hydock, D.S., Lien, C.Y., Schneider, C.M., et al. (2007) Effects of Voluntary Wheel Running on Cardiac Function and Myosin Heavy Chain in Chemically Gonadectomized Rats. American Journal of Physiology, Heart and Circulatory Physiology, 
293, H3254-H3264. https://doi.org/10.1152/ajpheart.00801.2007

[9] Cormie, P., Galvao, D.A., Spry, N., et al. (2014) Can Supervised Exercise Prevent Treatment Toxicity in Prostate Cancer Patients Initiating Androgen Deprivation Therapy: A Randomised Controlled Trial. BJU International.

[10] Bourke, L., Doll, H., Crank, H., et al. (2011) Lifestyle Intervention in Men with Advanced Prostate Cancer Receiving Androgen Suppression Therapy: A Feasibility Study. Cancer Epidemiology Biomarkers \& Prevention, 20, 647-657. https://doi.org/10.1158/1055-9965.EPI-10-1143

[11] Culos-Reed, S.N., Robinson, J.W., Lau, H., et al. (2010) Physical Activity for Men Receiving Androgen Deprivation Therapy for Prostate Cancer: Benefits from a 16-Week Intervention. Support Care Cancer, 18, 591-599. https://doi.org/10.1007/s00520-009-0694-3

[12] Segal, R.J., Reid, R.D., Courneya, K.S., et al. (2009) Randomized Controlled Trial of Resistance or Aerobic Exercise in Men Receiving Radiation Therapy for Prostate Cancer. Journal of Clinical Oncology, 27, 344-351. https://doi.org/10.1200/JCO.2007.15.4963

[13] Khan, K.M., Thompson, A.M., Blair, S.N., et al. (2012) Sport and Exercise as Contributors to the Health of Nations. The Lancet, 380, 59-64.

[14] Schmidt, J.F., Andersen, T.R., Horton, J., et al. (2013) Soccer Training Improves Cardiac Function in Men with Type 2 Diabetes. Medicine \& Science in Sports \& Exercise, 45, 2223-2233. https://doi.org/10.1249/MSS.0b013e31829ab43c

[15] Krustrup, P., Aagaard, P., Nybo, L., et al. (2010) Recreational Football as a Health Promoting Activity: A Topical Review. Scandinavian Journal of Medicine \& Science in Sports, 20, 1-13. https://doi.org/10.1111/j.1600-0838.2010.01108.x

[16] Schmidt, J.F., Hansen, P.R., Andersen, T.R., et al. (2014) Cardiovascular Adaptations to 4 and 12 Months of Football or Strength Training in 65- to 75-Year-Old Untrained Men. Scandinavian Journal of Medicine \& Science in Sports, 24, 86-97. https://doi.org/10.1111/sms.12217

[17] Krustrup, P., Randers, M.B., Andersen, L.J., et al. (2013) Soccer Improves Fitness and Attenuates Cardiovascular Risk Factors in Hypertensive Men. Medicine \& Science in Sports \& Exercise, 45, 553-560. https://doi.org/10.1249/MSS.0b013e3182777051

[18] Adamsen, L., Rasmussen, J.M. and Pedersen, L.S. (2001) "Brothers in Arms": How Men with Cancer Experience a Sense of Comradeship through Group Intervention Which Combines Physical Activity with Information Relay. Journal of Clinical Nursing, 10, 528-537. https://doi.org/10.1046/j.1365-2702.2001.00514.x

[19] Ottesen, L., Jeppesen, R.S. and Krustrup, B.R. (2010) The Development of Social Capital through Football and Running: Studying an Intervention Program for Inactive Women. Scandinavian Journal of Medicine \& Science in Sports, 1, 118-131. https://doi.org/10.1111/j.1600-0838.2010.01123.x

[20] Wisloff, U., Stoylen, A., Loennechen, J.P., et al. (2007) Superior Cardiovascular Effect of Aerobic Interval Training versus Moderate Continuous Training in Heart Failure Patients: A Randomized Study. Circulation, 115, 3086-3094. https://doi.org/10.1161/CIRCULATIONAHA.106.675041

[21] Guiraud, T., Nigam, A., Gremeaux, V., et al. (2012) High-Intensity Interval Training in Cardiac Rehabilitation. Sports Medicine, 42, 587-605. https://doi.org/10.2165/11631910-000000000-00000

[22] Andersen, L.J., Hansen, P.R., Sogaard, P., et al. (2010) Improvement of Systolic and 
Diastolic Heart Function after Physical Training in Sedentary Women. Scandinavian Journal of Medicine \& Science in Sports, 20, 50-57. https://doi.org/10.1111/j.1600-0838.2009.01088.x

[23] Mogelvang, R., Sogaard, P., Pedersen, S.A., et al. (2009) Cardiac Dysfunction Assessed by Echocardiographic Tissue Doppler Imaging Is an Independent Predictor of Mortality in the General Population. Circulation, 119, 2679-2685. https://doi.org/10.1161/CIRCULATIONAHA.108.793471

[24] Bovelli, D., Plataniotis, G. and Roila, F. (2010) Cardiotoxicity of Chemotherapeutic Agents and Radiotherapy-Related Heart Disease: ESMO Clinical Practice Guidelines. Annals of Oncology, 21, v277-v282. https://doi.org/10.1093/annonc/mdq200

[25] Mogelvang, R., Sogaard, P., Pedersen, S.A., et al. (2009) Tissue Doppler Echocardiography in Persons with Hypertension, Diabetes, or Ischaemic Heart Disease: The Copenhagen City Heart Study. European Heart Journal, 30, 731-739. https://doi.org/10.1093/eurheartj/ehn596

[26] Stanton, T., Leano, R. and Marwick, T.H. (2009) Prediction of All-Cause Mortality from Global Longitudinal Speckle Strain: Comparison with Ejection Fraction and Wall Motion Scoring. Circulation: Cardiovascular Imaging, 2, 356-364. https://doi.org/10.1161/CIRCIMAGING.109.862334

[27] Uth, J., Schmidt, J.F., Christensen, J.F., et al. (2013) Effects of Recreational Soccer in Men with Prostate Cancer Undergoing Androgen Deprivation Therapy: Study Protocol for the "FC Prostate" Randomized Controlled Trial. BMC Cancer, 13, 595. https://doi.org/10.1186/1471-2407-13-595

[28] Nagueh, S.F., Appleton, C.P., Gillebert, T.C., et al. (2009) Recommendations for the Evaluation of Left Ventricular Diastolic Function by Echocardiography. European Journal of Echocardiography, 10, 165-193. https://doi.org/10.1093/ejechocard/jep007

[29] Schiller, N.B., Acquatella, H., Ports, T.A., et al. (1979) Left Ventricular Volume from Paired Biplane Two-Dimensional Echocardiography. Circulation, 60, 547-555. https://doi.org/10.1161/01.CIR.60.3.547

[30] Unzek, S., Popovic, Z.B. and Marwick, T.H. (2011) Effect of Recommendations on Interobserver Consistency of Diastolic Function Evaluation. Cardiovascular Imaging, 4, 460-467.

[31] Leitman, M., Lysyansky, P., Sidenko, S., et al. (2004) Two-Dimensional Strain-A Novel Software for Real-Time Quantitative Echocardiographic Assessment of Myocardial Function. Journal of the American Society of Echocardiography, 17, 1021-1029.

[32] Sogaard, P., Egeblad, H., Pedersen, A.K., et al. (2002) Sequential versus Simultaneous Biventricular Resynchronization for Severe Heart Failure: Evaluation by Tissue Doppler Imaging. Circulation, 106, 2078-2084. https://doi.org/10.1161/01.CIR.0000034512.90874.8E

[33] Flammer, A.J., Anderson, T., Celermajer, D.S., et al. (2012) The Assessment of Endothelial Function: From Research into Clinical Practice. Circulation, 126, 753-767. https://doi.org/10.1161/CIRCULATIONAHA.112.093245

[34] Gillespie, C.D. and Hurvitz, K.A. (2013) Prevalence of Hypertension and Controlled Hypertension United States, 2007-2010. MMWR Surveillance Summaries, 62, 144-148.

[35] Cuspidi, C., Sala, C., Negri, F., et al. (2012) Prevalence of Left-Ventricular Hypertrophy in Hypertension: An Updated Review of Echocardiographic Studies. Journal of Human Hypertension, 26, 343-349. https://doi.org/10.1038/jhh.2011.104 
[36] Zwadlo, C., Schmidtmann, E., Szaroszyk, M., et al. (2015) Antiandrogenic Therapy with Finasteride Attenuates Cardiac Hypertrophy and Left Ventricular Dysfunction. Circulation, 131, 1071-1081. https://doi.org/10.1161/CIRCULATIONAHA.114.012066

[37] Yingchoncharoen, T., Agarwal, S., Popovic, Z.B., et al. (2013) Normal Ranges of Left Ventricular Strain: A Meta-Analysis. Journal of the American Society of Echocardiography, 26, 185-191.

[38] Arbab-Zadeh, A., Dijk, E., Prasad, A., et al. (2004) Effect of Aging and Physical Activity on Left Ventricular Compliance. Circulation, 110, 1799-1805. https://doi.org/10.1161/01.CIR.0000142863.71285.74

[39] Kuznetsova, T., Herbots, L., Lopez, B., et al. (2009) Prevalence of Left Ventricular Diastolic Dysfunction in a General Population. Circulation: Heart Failure, 2, 105-112. https://doi.org/10.1161/CIRCHEARTFAILURE.108.822627

[40] Utomi, V., Oxborough, D., Whyte, G.P., et al. (2013) Systematic Review and Meta-Analysis of Training Mode, Imaging Modality and Body Size Influences on the Morphology and Function of the Male Athlete's Heart. Heart, 99, 1727-1733. https://doi.org/10.1136/heartjnl-2012-303465

[41] Andersen, L.J., Randers, M.B., Hansen, P.R., et al. (2014) Structural and Functional Cardiac Adaptations to 6 Months of Football Training in Untrained Hypertensive Men. Scandinavian Journal of Medicine \& Science in Sports, 24, 27-35. https://doi.org/10.1111/sms.12237

[42] Schmidt, J.F., Andersen, T.R., Andersen, L.J., et al. (2013) Cardiovascular Function Is Better in Veteran Football Players than Age-Matched Untrained Elderly Healthy Men. Scandinavian Journal of Medicine \& Science in Sports.

[43] Alberga, A.S., Segal, R.J., Reid, R.D., et al. (2012) Age and Androgen-Deprivation Therapy on Exercise Outcomes in Men with Prostate Cancer. Support Care Cancer, 20, 971-981. https://doi.org/10.1007/s00520-011-1169-x

[44] Daussin, F.N., Zoll, J., Dufour, S.P., et al. (2008) Effect of Interval versus Continuous Training on Cardiorespiratory and Mitochondrial Functions: Relationship to Aerobic Performance Improvements in Sedentary Subjects. American Journal of Physiology. Regulatory, Integrative and Comparative Physiology, 295, R264-R272. https://doi.org/10.1152/ajpregu.00875.2007

[45] Nyberg, M., Blackwell, J.R., Damsgaard, R., et al. (2012) Lifelong Physical Activity Prevents an Age-Related Reduction in Arterial and Skeletal Muscle Nitric Oxide Bioavailability in Humans. The Journal of Physiology, 590, 5361-5370. https://doi.org/10.1113/jphysiol.2012.239053

[46] Rubinshtein, R., Kuvin, J.T., Soffler, M., et al. (2010) Assessment of Endothelial Function by Non-Invasive Peripheral Arterial Tonometry Predicts Late Cardiovascular Adverse Events. European Heart Journal, 31, 1142-1148. https://doi.org/10.1093/eurheartj/ehq010

[47] Jones, L.W., Hornsby, W.E., Freedland, S.J., et al. (2014) Effects of Nonlinear Aerobic Training on Erectile Dysfunction and Cardiovascular Function Following Radical Prostatectomy for Clinically Localized Prostate Cancer. European Urology, 65, 852-855.

[48] Cornelissen, V.A., Onkelinx, S., Goetschalckx, K., et al. (2014) Exercise-Based Cardiac Rehabilitation Improves Endothelial Function Assessed by Flow-Mediated Dilation But Not by Pulse Amplitude Tonometry. European Journal of Preventive Cardiology, 21, 39-48. https://doi.org/10.1177/2047487312460516

[49] Krustrup, P., Hansen, P.R., Randers, M.B., et al. (2010) Beneficial Effects of Recrea- 
tional Football on the Cardiovascular Risk Profile in Untrained Premenopausal Women. Scandinavian Journal of Medicine \& Science in Sports, No. 1, 40-49. https://doi.org/10.1111/j.1600-0838.2010.01110.x

[50] Bruun, D.M., Krustrup, P., Hornstrup, T., et al. (2014) "All Boys and Men Can Play Football": A Qualitative Investigation of Recreational Football in Prostate Cancer Patients. Scandinavian Journal of Medicine \& Science in Sports, No. 1, 113-121. https://doi.org/10.1111/sms.12193

\section{Scientific Research Publishing}

Submit or recommend next manuscript to SCIRP and we will provide best service for you:

Accepting pre-submission inquiries through Email, Facebook, LinkedIn, Twitter, etc. A wide selection of journals (inclusive of 9 subjects, more than 200 journals)

Providing 24-hour high-quality service

User-friendly online submission system

Fair and swift peer-review system

Efficient typesetting and proofreading procedure

Display of the result of downloads and visits, as well as the number of cited articles Maximum dissemination of your research work

Submit your manuscript at: http://papersubmission.scirp.org/

Or contact wjcd@scirp.org 